\title{
Developing a Virtual Safety Training Tool for Scaffolding and Formwork Activities
}

\author{
Gokhan KAZAR ${ }^{1}$ \\ Semra COMU ${ }^{2}$
}

\begin{abstract}
As occupational accidents usually occur due to unsafe human behaviours in the construction industry, safety training is inevitably necessary for site personnel. On construction sites, various training methods including traditional and innovative ones, have been adopted to prevent accidents. In recent years, virtual safety training has been more prevalent because of providing highly engaging practice in a risk-free environment. Although these training tools have innumerable advantages in providing safety knowledge and awareness, they can be further improved. This study introduces a virtual safety training tool, V-SAFE.v2, to provide a more reliable and effective safety training for high-risk construction works. V-SAFE.v2 consists of three main modules; i) Training Module, ii) Testing Module 1, and iii) Testing Module 2. These modules are generated firstly to provide safety training for scaffolding and formwork activities and then to evaluate the safety performance of the trainees. An experiment was conducted with fifteen construction workers and ten engineers to measure the effectiveness of the training tool. The findings showed that V-SAFE.v2 is a reliable safety training tool for high-risk construction tasks as it supports collaboration, provides individual feedback, and repeatable practice. Also, the participants stated that V-SAFE.v2 has a great potential to reduce the falling from height accidents in the construction workplaces.
\end{abstract}

Keywords: Occupational safety, training, serious game, scaffolding, formwork.

\section{INTRODUCTION}

Due to the heavy work environment and complex tasks involved, construction sites have become one of the most hazardous workplaces. Statistics also show that the construction industry has the highest rate for occupational fatalities and injuries all around the world. There are approximately 60.000 occupational deaths in the construction industry every year [1]. According to the report of Bureau of Labor Statistics, while 5.5\% of total workers are

Note:

- This paper has been received on March 30, 2020 and accepted for publication by the Editorial Board on November 9, 2020.

- Discussions on this paper will be accepted by May 31, 2020.

- https://doi.org/10.18400/tekderg.711091

1 Istanbul Gedik University, Department of Civil Engineering, Istanbul, Turkey gokhan.kazar@gedik.edu.tr - https://orcid.org/0000-0002-8616-799X

2 Bogazici University, Department of Civil Engineering, Istanbul, Turkey semra.comu@boun.edu.tr - https://orcid.org/0000-0001-5733-6195 
employed in the construction industry, the fatality rate of construction works is approximately $20 \%$ in the U.S, which is higher than other sectors [2]. Such rates clearly show that construction sites have poor working conditions in terms of occupational safety and health. Despite giving more attention to safety issues for the last years, the number of construction accidents remains high. Therefore, there are high debates and concerns about the root causes of accidents in the construction industry. It is highly emphasized that human behaviour is one of the most important factors in occupational fatalities and injuries. Haslam et al. [3] noticed that $70 \%$ of the accidents occur due to unsafe behaviour of workers on construction sites, which shows the role of human factors in accidents. Besides, Guo and his colleagues [4] also stated that most of the accidents occurred because of inadequate safety consciousness of workers during the construction tasks. To eliminate such human-based problems, it is a well-known fact that safety training is the most efficient method. However, the effectiveness of safety training is another crucial point in the construction industry. Thus, alternative training techniques should be developed and provided to increase the reliability of safety training.

\section{BACKGROUND}

As known, construction works are very dangerous and carry a high risk for workers. Thus, the attitudes of workers during complex tasks might have catastrophic consequences on construction sites. In most of the previous studies, the significant correlation between unsafe human actions and construction accidents is highlighted [5-7]. For instance, Kale et al. [5] found that the factor of unsafe human activity is one of the most crucial root causes of occupational accidents in the construction industry. Moreover, the role of the human factors in construction accidents are indicated in a previous study [6]. According to the results of a previous study [7], the safety performance of the workers plays a major role in occupational accidents. In addition to unsafe human behaviour, the lack of appropriate safety training is one of the most important factors contributing to high fatality in the construction industry [9]. Previous studies in the field of construction safety emphasize that training is the most efficient human-based prevention method and should be provided to the construction workers [9-12]. Abdelhamid and Everett [9] suggest a relation between failing to identify unsafe conditions and worker training. Similarly, another research [12] found that worker actions were the main causal factor in accidents. In this context, Zhao and his colleagues [11] investigated the causes of electrocution in the U.S. construction industry. They [11] concluded that unsafe worker behaviour is the main cause of electrical fatalities and injuries. Tam and Fung [10] argue that behaviour-based safety training method has significant potential in reducing tower crane accidents. Therefore, an improperly trained worker may not be able to recognize the potential risks associated with construction works and avoid risky behaviour. Hence, more emphasis has recently been given to providing effective and adequate safety training to improve the safety performance of construction workers. Safety training methods can be grouped as i) traditional safety training programs and, ii) advanced technology-enabled safety training methods, to reduce the number of injuries and fatal accidents in construction workplaces. 


\subsection{Traditional Safety Training Methods}

Until recently, safety training was generally provided by traditional methods in the construction industry. Zhao and Lucas [13] classified traditional safety training methods into three main categories; a) classroom training b) on-site training c) safety meetings. During classroom training, safety knowledge is just transferred only through videos, presentations, and guides. On the other hand, the employees are trained through practical applications such as the use of real tools, machines, and equipment in the on-site training method. Finally, safety meetings are held by providing presentation slides, videos, and weekly talks on safety issues encountered at construction sites [13]. Several studies provided traditional training methods to improve the safety performances of workers [14-15]. Jeschke and colleagues [14] developed a toolbox-training program aimed at improving the quality of collaboration between the project personnel on safety issues during the construction phases. The researchers used the classroom training method and 57 construction workers participated in the safety training program. A questionnaire and interview were conducted with the participants to understand the applicability of such a training method. Based on the assessments, they found that the toolbox meeting program of the trainees was beneficial and positively influenced daily work processes in terms of safety. In another study by Hinze [15], traditional safety training programs have been proposed to reduce accident rates in the construction industry. The researcher analysed major construction sites where safety training was provided based on the regulations of the Occupational Safety and Health Administration (OSHA). The results of the study show that the safety performances of large construction companies are significantly better concerning the general construction industry because of providing OSHA safety regulations [15].

On the other hand, several studies [16-17] show that traditional safety training methods are not as effective and reliable as desired. Such off-site training methods do not provide sufficient practice to experience intensively real working environments. Besides, the trainees are usually passive and bored during traditional training, which has a significant negative impact on their motivation [16]. As stated by Li et al. [18] an on-site training method could be an alternative solution to address the inefficiency of traditional safety training methods. Nevertheless, it is not widely preferred because it is time-consuming, expensive, requires special equipment, and carries real accident risks for trainees. Thus, today the majority of safety training has been delivered in classrooms through written documents, presentations, videos, and safety meetings at the construction sites. Due to the deficiencies of current safety training methods, recent studies have focused heavily on advanced technology-based safety training tools to improve the efficiency of safety training programs.

\subsection{Serious Games for Advanced Technology-Enabled Safety Training}

Recently, computer-based safety training tools have been more attractive in the field of construction safety to enhance the safety culture of employees. Especially those based on game-engine are more effective in developing safety knowledge and raising risk awareness due to providing interactive engagement and a risk-free environment [18]. Accordingly, construction safety training tools have been developed in recent years by using game technologies called serious games. 
Serious games, a type of computer game, are designed to address real-life problems rather than entertainment goals [19]. Mertens et al. [20] stated that a serious game or game-based education integrates learning, games, and simulation components. Through the use of serious games, players can perform scenario-based tasks collaboratively and develop safety knowledge in simulated workplaces. Another advantage of serious games is that trainees can perceive the direct results of their activities on virtual platforms without experiencing their real impacts [21].

To date, serious games have been utilized for safety training in different areas such as aviation [22], medical [23], and military [24]. Also, game engine-based safety training tools have been widely utilized for construction tasks. They were developed for different application purposes including, hazard identification [25-27] delivering instructions for construction methods [28] and occupational safety training [29-30]. Pedro and his colleagues [27] introduced a game engine-based training tool that enables us to identify potential construction site hazards in a virtual environment. The training tool titled VSES consists of three different parts; a) Safety and Hazard Lecture b) Hazard Identification Game and c) Student Evaluation and Assessment modules. The first module was developed to support students to acquire safety knowledge and raise awareness of workplace hazards. The purpose of the second module is to allow virtual construction sites to be experienced and to identify the construction site risks introduced in the first module. The third module was designed to evaluate participants according to their safety performance. Fang and Teizer [29] presented a multiuser serious game that provides interactive safety training for crane operators. In this study, there are great efforts on developing an actual construction site conditions and simple game logic that can effectively train crane operators. They proposed a novel approach for crane operations to prevent accidents caused by blind points. One crane operator and a signalling person play together to lift loads safely from one place to another. The crane operator works in collaboration with the signalling player who warns the crane operator for blind points during the hoisting operation in the virtual environment.

Studies in the field of construction safety have confirmed that the usage of serious games provides important opportunities for trainees to develop safety knowledge and meet desired training objectives. Moreover, such previous initiatives prove that game-based training methods are more reliable and effective than conventional methods for construction works. However, there are still deficiencies in serious game-based training in terms of presenting all real construction site dynamics.

\subsection{Scaffolding and Formwork Accidents}

On construction sites, falling from height is the main cause of high fatality rates worldwide. For example, fall-related occupational deaths account for about $39 \%$ of all construction fatal accidents in the U.S [31]. This type of catastrophic accident occurs to a large extent during the use of temporary structures such as scaffolds [7, 32] and formworks [33]. Although diverse tasks are performed in the construction industry, $65 \%$ of such works are carried out by using scaffolding or such temporary structures [34]. Also, formwork is another common type of work for concrete structures. Therefore, there are many concerns about accidents related to the scaffolding [35-36] and formwork construction [37-38] to reduce accidents. Gürcanlı and Müngen [36] classified the main causes of incidences in the Turkish 
construction industry. They revealed that the falls from scaffolds and roofs (54\%) and falling objects $(12 \%)$ were more likely to be encountered in the construction workplaces. RubioRomero et al. [31] investigated the safety conditions of scaffolds and evaluated 105 scaffolds installed at construction sites in Spain. The results of this study demonstrated that the general safety condition of non-standardized scaffolds is poor in terms of using anchor-tie, base plates, and walking platforms. Lopez-Arquillos et al. [38] evaluated the riskiest activities in vertical concrete formwork construction, such as columns and walls. According to the results, formwork construction, climbing ladders, and handling an object during the construction process were the highest risk activities for workers. Based on the literature review, it can be concluded that both scaffolding and formwork activities have a crucial role in common types of accidents, such as falling from a height, scaffold collapse, and falling objects. As a result, effective and reliable safety training methods are needed to prevent such accidents related to scaffolding and formwork construction.

\subsection{Requirements of Safety Training Tools}

Although serious games have been utilized as safety training tools in the field of construction safety, the reliability, applicability, and effectiveness of these tools can be further improved. For example, Zhou et al. [39] stated that only a few studies were conducted specifically for certain tasks such as working at height. Even though falling from height is one of the most prevalent accident types in construction sites [41], there are only a few serious game-based safety training tools that support working at height or similar construction tasks (e.g. [40,42]). Also, although many construction safety studies have concentrated on general safety training process (e.g. [30, 43]) and equipment operation (e.g. $[29,45])$, the limited number of research (e.g. [27]) integrated a potential accident scenario in the game engine-based training tools.

Virtual safety training tools should enable participants to experience the consequence of their actions. When they make a mistake during the training, an accident should have occurred, which provides a more realistic experience of fatalities or injuries. Another important aspect is the collaboration between the workers during the construction activities. It is a well-known fact that the construction tasks require high interaction among the crew members. Hence, previous studies on safety training tools [18] and occupational accidents [3] recommend that future game engine-based training tools should be heavily built on collaborative tasks to improve the teamwork culture. In addition, the tools should not only focus on a sequencebased training process but also provide a behavioural improvement related to the use of Personal Protective Equipment (PPE), which is another common problem at construction sites [3]. Another key problem is that the existing game engine-based safety training tools have not been adequately tested by using actual construction workers. Zhou et al. [39] stated that user-friendly components should be embedded in training tools and easily practiced with real construction workers. These limitations indicate a high demand for multi-user, serious game-based safety training tools including accident scenarios on specific construction tasks to achieve more effective and realistic training objectives. In addition, they should be tested with real construction workers and received feedback from them about the safety training tool. For these reasons, this study aims to develop and test a serious game-based safety training tool to meet the requirements of serious games on construction safety training. 


\section{RESEARCH METHODOLOGY}

This study introduces and tests the second version of a serious game-based safety training tool, called V-SAFE.v2, for scaffolding and formwork activities. The first version of VSAFE was developed to simulate the tower crane operations in the construction sites [46]. In the research methodology section, the scenario development process for scaffolding and formwork tasks is initially explained, and then the general functions of the safety training tool are introduced. After that, the modules of V-SAFE.v2 are described in detail. At the end of this section, a case study is conducted to understand the effectiveness and applicability of V-SAFE.v2 with actual construction workers and engineers.

\subsection{Scenario Development for Construction Tasks}

The game engine-based safety training tool, V-SAFE.v2, incorporates a novel and more realistic scenario aimed at meeting the requirements of serious games for safety training. $\mathrm{V}$ SAFE.v2 consists of construction activities, particularly related to scaffolding and formwork construction. For example, the scenario offers training opportunities on wearing a hardhat, using a safety harness, installation of guardrails and catwalks, and locking the pins during formwork and scaffolding construction. In general, the frequent root-causes of incidents are related to such activities at construction sites [5, 47]. Therefore, the common unsafe work systems leading to serious accidents and affecting overall construction workflow were included in a single scenario. The scenario steps in V-SAFE.v2, consisting of the H-Frame scaffolding system and the concrete column formwork, are shown in the following flow chart (Figure 1).

In the scenario, trainees are initially directed to the storage area where they can get standard PPEs such as gloves, glasses, hardhat, lanyard (Figure 2). The participants are then asked to go to the material storage area to pick up the necessary materials such as a toolbox, $\mathrm{H}$-frames, base plates, plywood, pins, set of diagonal bars for scaffolding and formwork tasks. Afterward, participants perform scenario-based construction tasks during the training process. Finally, after completing all tasks, the trainees are ready to work at height (Figure $3)$.

\subsection{System Architecture of V-SAFE.v2}

V-SAFE.v2 was developed based on the Unity 3D game engine introduced by Unity Technologies. The Unity 3D game engine allows developers to create a virtual and multiuser interactive gaming platform by using appropriate 3D images, which makes it one of the most suitable environments for serious games. Moreover, SCORM is utilized to create a Learning Management System (LMS) platform in V-SAFE.v2 as it is the most widely used e-learning standard. LMS is a widely used online platform for e-learning and provides monitoring of a training or education process. Besides, Recording System (RS) is another crucial component in V-SAFE.v2. It is possible to record the safety performance of participants and publish a trainee's performance report for each construction task via LMS and RS. The recorded data on safety training performance is always available for trainers in the cloud-based platform. The LMS and RS are automatically enabled for each player when they sign in the safety training platform. V SAFE.v2 has both single-player and multiplayer 
facilities, and SCORM is compatible with both single-player and multiplayer games. Therefore, it is available that all users together can receive training on a single platform (Figure 4).

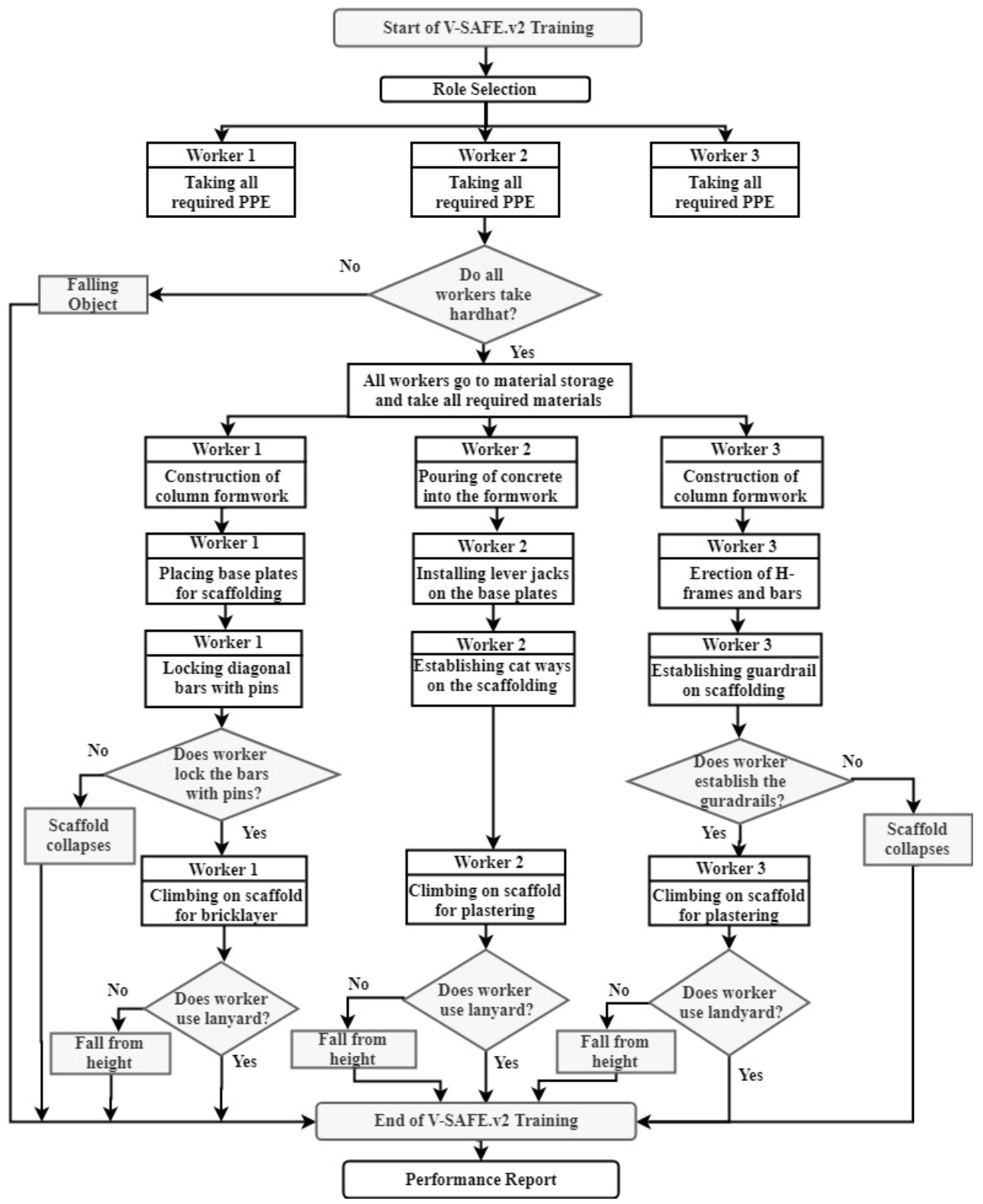

Figure 1 - Developed task workflow for V-SAFE.v2 


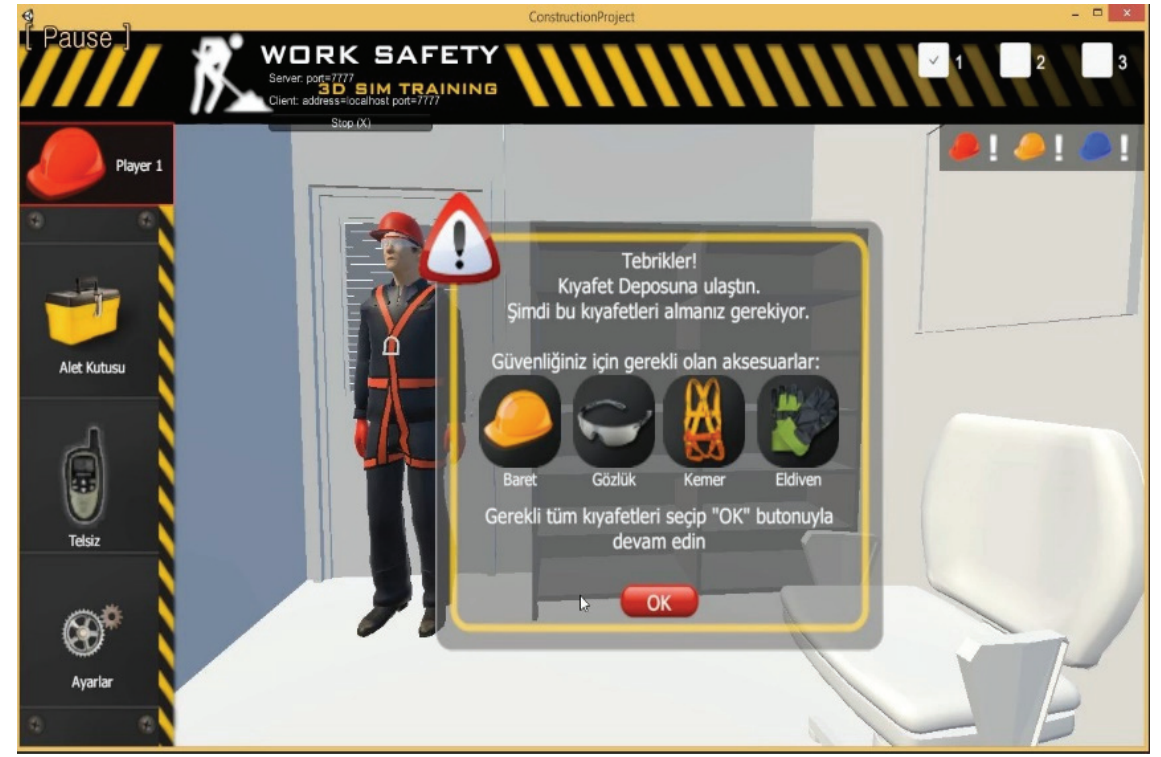

Figure 2 - PPE store

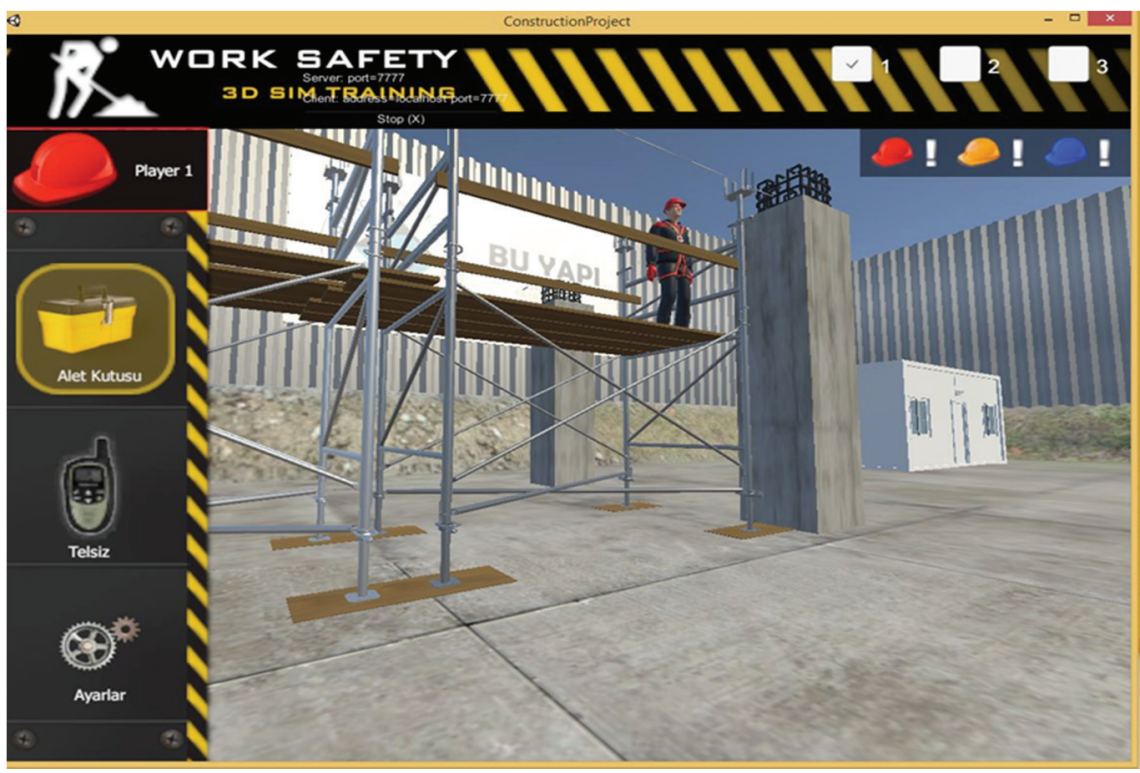

Figure 3 - Guardrails and catwalks 


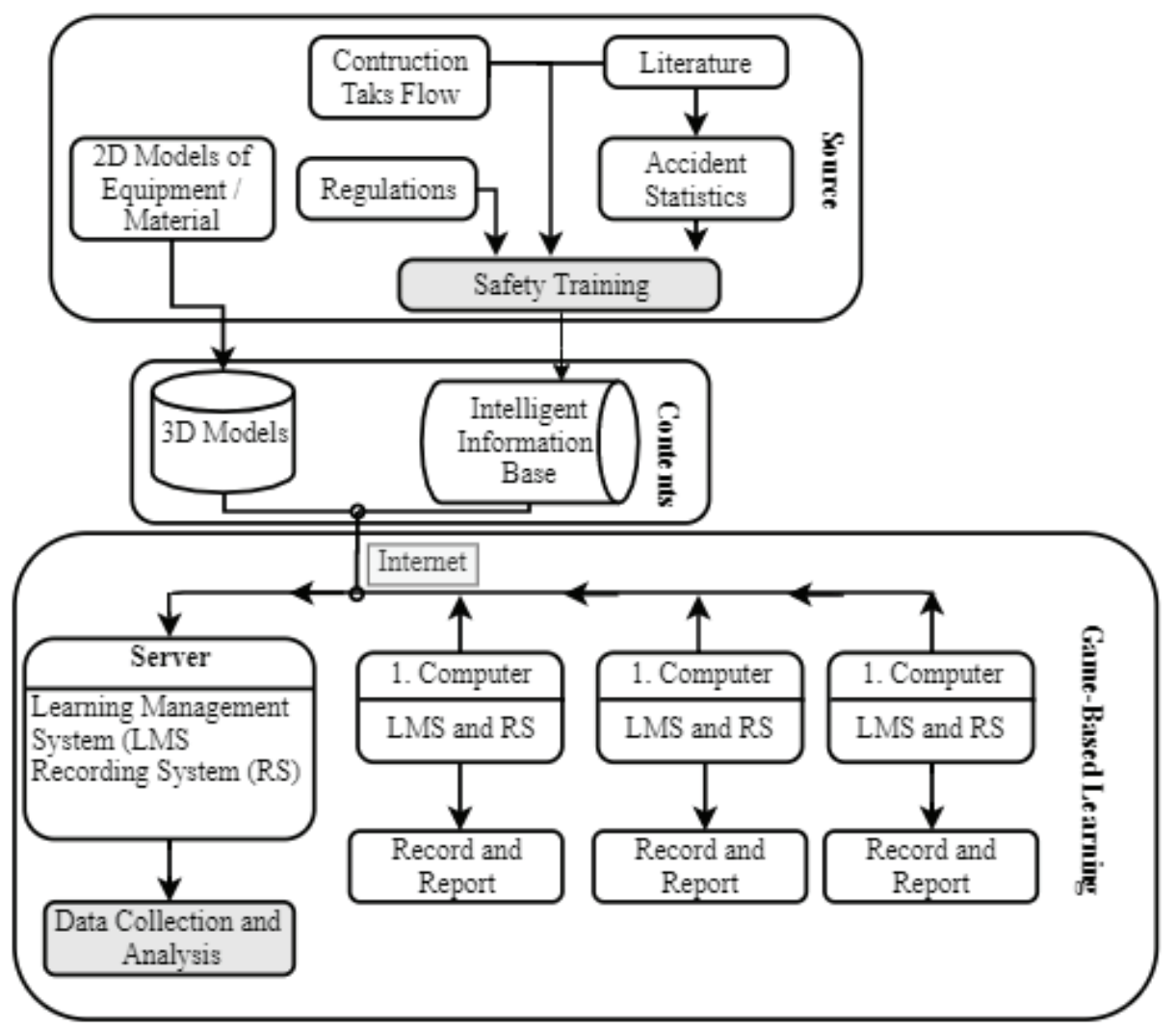

Figure 4 - System architecture of V-SAFE.v2

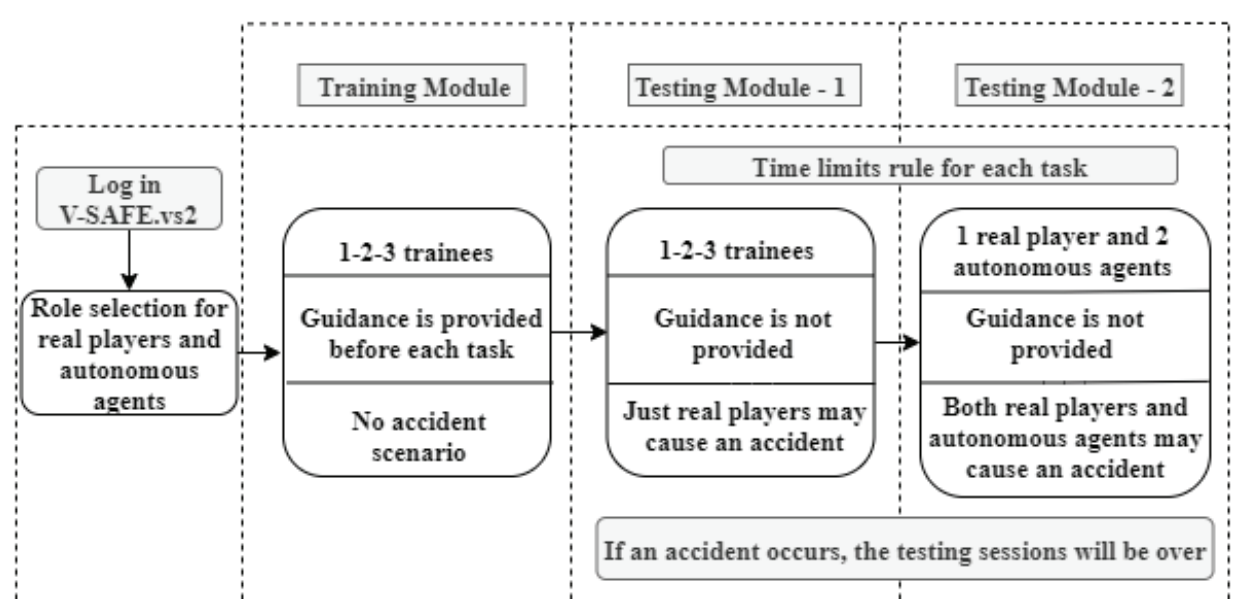

Figure 5 - Modules of V-SAFE.v2 
The training and testing processes of V-SAFE.v2 are designed for three users, but the number of participants can be increased. Participants are initially asked to select their roles from three different options when they start the training session. V-SAFE.v2 uses a third-person perspective to enable a better understanding of the scene. Also, the point and click mechanism is preferred to provide a more user-friendly system. Moreover, the trainees can contact each other to call for help and learn about the construction work process. The system also allows fewer than three participants to receive training. In this case, other roles are supported by autonomous agents known as a character controlled by computers. Autonomous agents can fulfil construction tasks both in compliance and non-compliance with safety rules. They are especially beneficial in providing a multi-user game environment when only a single participant receives training. In addition, such non-playable characters are also utilized in accident scenarios. V-SAFE.v2 has three different modules including; i) Training Module ii) Testing Module 1 iii) Testing Module 2, as illustrated in Figure 5.

\subsubsection{Training Module}

In the training module, step by step instructions for scaffolding and formwork tasks and highly engaging safety training is provided to the participants. Instructions and necessary cautionary messages on how trainees should perform each task are shown before each step. The integrated flashing objects direct trainees to the material storage or workplaces where they should go in V-SAFE.v2. They solely click on the flashing places or objects, and their avatars automatically move toward there. Besides, the trainees can walk through the virtual construction site and explore their workplaces. While three participants can receive training at the same time, only a single participant or two participants can also receive training with the support of autonomous agents.

\subsubsection{Testing Module - 1}

Upon successful completion of the training process, the trainees can move on to the next part, the Testing Module 1 . The objective of this module is to assess the safety knowledge acquired in the Training Module and evaluate the performance of trainees without providing any guidance. In this module, the users have to make their decisions for each construction activity in 60 seconds. If the player does not act in a given time, the system accepts that the activity is not carried out, which may cause an accident based on the construction accident scenario.

In this first Testing Module, autonomous agents fulfil construction tasks in compliance with safety rules. Therefore, autonomous agents do not cause any incidence in this module, which is an important feature that allows observing only the individual performance of a real participant.

\subsubsection{Testing Module - 2}

Only a single trainee with two autonomous agents can carry out the tasks in the Testing Module 2. In this module, the autonomous agents could also exhibit unsafe occupational behaviour and lead to an accident identified in the scenario. Autonomous agents randomly cause an accident, according to predefined probabilities. The main purpose of this module is 
to provide trainees with accident experiences that may result in fatality or injury, even if they have successfully carried out all construction tasks. Accordingly, the awareness of trainees about occupational accident risks can be increased.

\subsection{Identified Accident Types in V-SAFE.v2}

Although there are various activities carried out on construction sites, some of them involve risks that can lead to fatal or serious injury accidents. According to the report of BLS [48], $72 \%$ of total injuries and fatalities have occurred due to scaffold-related accidents in the US. Among these accidents, falling from height and falling objects were found to be more dangerous and more frequent than other accident types [31,48]. Therefore, the common root causes and incidence rates of these accidents were identified and included in the construction scenario of V-SAFE.v2. For this purpose, we utilized a previous study by Whitaker et al. [47] to understand the causes of scaffold accidents. Whitaker and his colleagues [47] examined 3096 construction accident reports on scaffolding to understand the root causes of such cases. They classified the root causes of scaffold accidents as falling, collapsing, and falling objects according to the frequency of occurrence. Accident probability was calculated by dividing the number of accidents in each accident type by the total number of accidents. For instance, the absence of guardrails or edge protection systems is a common reason for the falls from height, which constitutes approximately $28 \%$ of the total scaffold-related accidents. Similarly, the failure to lock the pins to connect the $\mathrm{H}$ bars as the most prevalent reason causes about $30 \%$ of the scaffold collapses. Another major reason for falls at scaffolds is that workers do not usually use lanyards when working on such temporary structures. In addition, accidents when working on scaffolding are also caused by falling objects if workers do not wear a hardhat. Accidents due to falling objects account for $13 \%$ of the total scaffold related accidents (Table 1). Accordingly, if a trainee exhibits one of the unsafe behaviours, which is the main cause of an accident, the relevant accident scenario is realized according to calculated probability in V-SAFE.v2. On the other hand, the autonomous agents could randomly cause identified accidents based on the probabilities shown in Table 1.

Table 1 - Root Causes of Scaffold Accidents

\begin{tabular}{cll}
\hline Root Cause of Accident & Accident Type & Ratio \\
\hline Not Wearing Hardhat & Falling Objects & $13.5 \%$ \\
\hline Absence of Guardrails & Fall from a Height & $28.5 \%$ \\
\hline Not Locking Pins & Scaffold Collapses & $30.5 \%$ \\
\hline Not Using Safety Harnesses & Fall from a Height & $27.5 \%$ \\
\hline
\end{tabular}

\subsection{A Case Study}

To evaluate the effectiveness and applicability of the game engine based safety training tool, we tested V-SAFE.v2 with real workers and engineers. To this end, fifteen workers who work at a height in the construction sites and ten civil engineers received training in V-SAFE.v2. Since the main target of the case study is to observe the individual performance of 
participants, only the Training and Testing Module-1 were applied (Figure 6). The test performance of each player was automatically scored via the LMS and provided for each trainee at the end of virtual training.

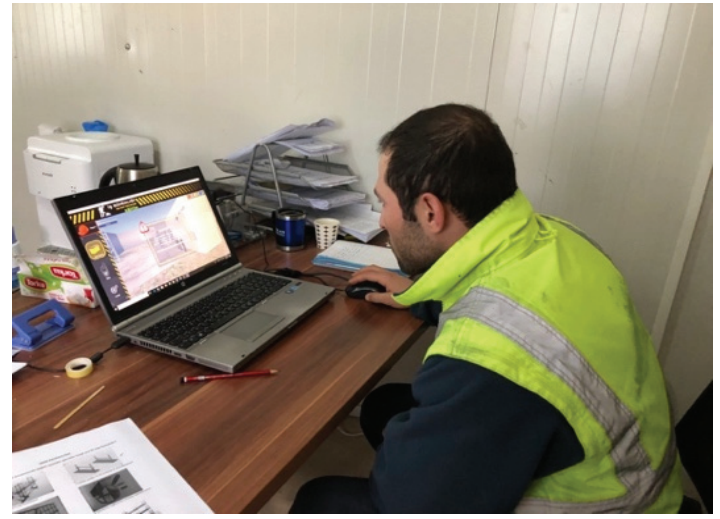

Figure 6 - Application of V-SAFE.v2 with a worker

\section{RESULTS AND DISCUSSION}

A total of 25 participants (15 workers and 10 engineers) attended training sessions in $\mathrm{V}$ SAFE.v2. There are 13 different construction activities in the tool with certain scores according to their risk levels. For example, tasks with a high risk of accidents such as using safety harness and hardhat, and installing guardrails and pins, have higher weights for scoring (Table 2). At the end of the simulation, the total score is calculated and normalized to 100 by the LMS and presented to the players as feedback.

The participants who received safety training in V-SAFE.v2 showed high performance in the first Testing Module. Almost all of the trainees received higher than 90 points (Table 2), and the average testing score of all participants is around 97. The high-performance scores indicate easy adaptation to V-SAFE.v2. Knowing that engagement or adaptation to a game is a crucial indicator for its effectiveness (e.g. $[19,24]$ ), we claim that V-SAFE.v2 provides effective safety training. According to the performance results, six participants forgot to lock the pins, which is a common reason for serious scaffolding accidents in real construction sites, as stated by Whitaker and colleagues [47]. Like in a real construction site, forgetting to lock the pins also leads to scaffold collapse in the virtual environment, and their training session ended (Figure 7).

It should also be emphasized that most of the real workers either do not have any computer game experience or they have very limited experience. Since the target audience of this safety training tool is real workers, especially those who erect the scaffolds and carry out formwork activities in construction sites, V-SAFE.v2 has been designed to be as user-friendly as possible using point and click function, flashing objects and guiding texts. Moreover, the participants can identify their deficiencies and weaknesses related to scaffolding and formwork construction tasks based on the provided elaborate performance report. One of the main contributions of this study is that the V-SAFE.v2 training tool has the potential to be 
convenient for all users, especially construction workers who are not familiar with computer games and virtual technologies. It is emphasized by Zhou et al. [39, 49] that there is also an implementation problem of the safety training tools developed in previous studies. Thus, we propose that the easy applicability of V-SAFE.v2 overcome the implementation issue.

Table 2 - Construction Tasks in V-SAFE.v2

\begin{tabular}{|c|c|c|c|c|c|c|c|c|c|c|c|c|c|c|}
\hline & \multicolumn{5}{|c|}{ Taking } & \multicolumn{7}{|c|}{ Installing } & \multirow{2}{*}{\begin{tabular}{|c|} 
Using \\
Safety \\
Harness \\
\end{tabular}} & \multirow[b]{2}{*}{$\begin{array}{l}\text { Total } \\
\text { Score }\end{array}$} \\
\hline & Hardhat & \begin{tabular}{|c|} 
Safety \\
Harness \\
\end{tabular} & Glass & Gloves & $\begin{array}{l}\text { Tool } \\
\text { Box }\end{array}$ & $\begin{array}{l}\text { Base } \\
\text { Plate }\end{array}$ & $\begin{array}{c}\text { Jack } \\
\text { Stand }\end{array}$ & H Bars & $\begin{array}{c}\text { Diagonal } \\
\text { Bars }\end{array}$ & Pins & Catwalk & Guardrail & & \\
\hline Task Weights & 4 & 1 & 1 & 1 & 1 & 1 & 1 & 1 & 1 & 4 & 1 & 4 & 4 & \\
\hline Worker 1 & $\checkmark$ & $\checkmark$ & $\checkmark$ & $\checkmark$ & $\checkmark$ & $\checkmark$ & $\checkmark$ & $\checkmark$ & $\checkmark$ & $\checkmark$ & $\checkmark$ & $\checkmark$ & $\checkmark$ & 100 \\
\hline Worker 2 & $\checkmark$ & $\checkmark$ & $\checkmark$ & $\checkmark$ & $\checkmark$ & $\checkmark$ & $\checkmark$ & $\checkmark$ & $\checkmark$ & $\checkmark$ & $\checkmark$ & $\checkmark$ & $\checkmark$ & 100 \\
\hline Worker 3 & $\checkmark$ & $\checkmark$ & $\checkmark$ & $\checkmark$ & $\checkmark$ & $\checkmark$ & $\checkmark$ & $\checkmark$ & $\checkmark$ & $\checkmark$ & $\checkmark$ & $\checkmark$ & $\checkmark$ & 100 \\
\hline \begin{tabular}{|l} 
Worker 4 \\
\end{tabular} & $\checkmark$ & $\checkmark$ & $\checkmark$ & $\checkmark$ & $\checkmark$ & $\checkmark$ & $\checkmark$ & $\checkmark$ & $\checkmark$ & $x$ & $\checkmark$ & $\checkmark$ & $x$ & 92 \\
\hline Worker 5 & $\checkmark$ & $\checkmark$ & $\checkmark$ & $\checkmark$ & $\checkmark$ & $\checkmark$ & $\checkmark$ & $\checkmark$ & $\checkmark$ & $\checkmark$ & $x$ & $x$ & $x$ & 91 \\
\hline Worker 6 & $\checkmark$ & $\checkmark$ & $\checkmark$ & $\checkmark$ & $\checkmark$ & $\checkmark$ & $\checkmark$ & $\checkmark$ & $\checkmark$ & $x$ & $\checkmark$ & $\checkmark$ & $x$ & 92 \\
\hline Worker 7 & $\checkmark$ & $\checkmark$ & $\checkmark$ & $\checkmark$ & $\checkmark$ & $\checkmark$ & $\checkmark$ & $\checkmark$ & $\checkmark$ & $\checkmark$ & $\checkmark$ & $\checkmark$ & $\checkmark$ & 100 \\
\hline Worker 8 & $\checkmark$ & $\checkmark$ & $\checkmark$ & $\checkmark$ & $\checkmark$ & $\checkmark$ & $\checkmark$ & $\checkmark$ & $\checkmark$ & $x$ & $x$ & $x$ & $x$ & 83 \\
\hline \begin{tabular}{|l|} 
Worker 9 \\
\end{tabular} & $\checkmark$ & $\checkmark$ & $\checkmark$ & $\checkmark$ & $\checkmark$ & $\checkmark$ & $\checkmark$ & $\checkmark$ & $\checkmark$ & $\checkmark$ & $\checkmark$ & $\checkmark$ & $\checkmark$ & 100 \\
\hline \begin{tabular}{|l|} 
Worker 10 \\
\end{tabular} & $\checkmark$ & $\checkmark$ & $\checkmark$ & $\checkmark$ & $\checkmark$ & $\checkmark$ & $\checkmark$ & $\checkmark$ & $\checkmark$ & $\checkmark$ & $\checkmark$ & $\checkmark$ & $\checkmark$ & 100 \\
\hline \begin{tabular}{|l|} 
Worker 11 \\
\end{tabular} & $\checkmark$ & $\checkmark$ & $\checkmark$ & $\checkmark$ & $\checkmark$ & $\checkmark$ & $\checkmark$ & $\checkmark$ & $\checkmark$ & $\checkmark$ & $\checkmark$ & $\checkmark$ & $\checkmark$ & 100 \\
\hline Worker 12 & $\checkmark$ & $\checkmark$ & $\checkmark$ & $\checkmark$ & $\checkmark$ & $\checkmark$ & $\checkmark$ & $\checkmark$ & $\checkmark$ & $\checkmark$ & $\checkmark$ & $\checkmark$ & $\checkmark$ & 100 \\
\hline \begin{tabular}{|l|} 
Worker 13 \\
\end{tabular} & $\checkmark$ & $\checkmark$ & $\checkmark$ & $\checkmark$ & $\checkmark$ & $\checkmark$ & $\checkmark$ & $\checkmark$ & $\checkmark$ & $\checkmark$ & $\checkmark$ & $\checkmark$ & $\checkmark$ & 100 \\
\hline Worker 14 & $\checkmark$ & $\checkmark$ & $\checkmark$ & $\checkmark$ & $\checkmark$ & $\checkmark$ & $\checkmark$ & $\checkmark$ & $\checkmark$ & $\checkmark$ & $\checkmark$ & $\checkmark$ & $\checkmark$ & 100 \\
\hline Worker 15 & $\checkmark$ & $\checkmark$ & $\checkmark$ & $\checkmark$ & $\checkmark$ & $\checkmark$ & $\checkmark$ & $\checkmark$ & $\checkmark$ & $\checkmark$ & $\checkmark$ & $\checkmark$ & $\checkmark$ & 100 \\
\hline Engineer 1 & $\bar{c} \checkmark$ & $\sqrt{2}$ & $\bar{c} \checkmark$ & $\bar{c} \checkmark$ & $\sqrt{ } \checkmark$ & $\bar{c} \checkmark$ & $\checkmark$ & $\checkmark$ & $\checkmark$ & $\bar{x}$ & $\bar{\nabla}$ & $\checkmark$ & $\bar{x}$ & 92 \\
\hline \begin{tabular}{|l|} 
Engineer 2 \\
\end{tabular} & $\checkmark$ & $\checkmark$ & $\checkmark$ & $\checkmark$ & $\checkmark$ & $\checkmark$ & $\checkmark$ & $\checkmark$ & $\checkmark$ & $\checkmark$ & $\checkmark$ & $\checkmark$ & $\checkmark$ & 100 \\
\hline Engineer 3 & $\checkmark$ & $\checkmark$ & $\checkmark$ & $\checkmark$ & $\checkmark$ & $\checkmark$ & $\checkmark$ & $\checkmark$ & $\checkmark$ & $\checkmark$ & $\checkmark$ & $\checkmark$ & $\checkmark$ & 100 \\
\hline Engineer 4 & $\checkmark$ & $\checkmark$ & $\checkmark$ & $\checkmark$ & $\checkmark$ & $\checkmark$ & $\checkmark$ & $\checkmark$ & $\checkmark$ & $\checkmark$ & $\checkmark$ & $\checkmark$ & $\checkmark$ & 100 \\
\hline Engineer 5 & $\checkmark$ & $\checkmark$ & $\checkmark$ & $\checkmark$ & $\checkmark$ & $\checkmark$ & $\checkmark$ & $\checkmark$ & $\checkmark$ & $\checkmark$ & $\checkmark$ & $\checkmark$ & $\checkmark$ & 100 \\
\hline Engineer 6 & $\checkmark$ & $\checkmark$ & $\checkmark$ & $\checkmark$ & $\checkmark$ & $\checkmark$ & $\checkmark$ & $\checkmark$ & $\checkmark$ & $\checkmark$ & $\checkmark$ & $\checkmark$ & $\checkmark$ & 100 \\
\hline Engineer 7 & $\checkmark$ & $\checkmark$ & $\checkmark$ & $\checkmark$ & $\checkmark$ & $\checkmark$ & $\checkmark$ & $\checkmark$ & $\checkmark$ & $x$ & $\checkmark$ & $\checkmark$ & $x$ & 92 \\
\hline \begin{tabular}{|l|} 
Engineer 8 \\
\end{tabular} & $\checkmark$ & $\checkmark$ & $\checkmark$ & $\checkmark$ & $\checkmark$ & $\checkmark$ & $\checkmark$ & $\checkmark$ & $\checkmark$ & $\checkmark$ & $\checkmark$ & $\checkmark$ & $\checkmark$ & 100 \\
\hline \begin{tabular}{|l|} 
Engineer 9 \\
\end{tabular} & $\checkmark$ & $\checkmark$ & $\checkmark$ & $\checkmark$ & $\checkmark$ & $\checkmark$ & $\checkmark$ & $\checkmark$ & $\checkmark$ & $x$ & $\checkmark$ & $\checkmark$ & $x$ & 92 \\
\hline \begin{tabular}{|l} 
Engineer 10 \\
\end{tabular} & $\checkmark$ & $\checkmark$ & $\checkmark$ & $\checkmark$ & $\checkmark$ & $\checkmark$ & $\checkmark$ & $\checkmark$ & $\checkmark$ & $\checkmark$ & $\checkmark$ & $\checkmark$ & $\checkmark$ & 100 \\
\hline
\end{tabular}

Moreover, we also collected feedback on V-SAFE.v2 from the participants. Engineers emphasized the effectiveness of V-SAFE.v2 in terms of time and cost-benefit in creating safety awareness compared to on-site and classroom training methods. They also noticed that V-SAFE.v2 involved complex and hazardous construction tasks in a realistic scenario flow affecting the learning process. All of the participants agreed that the introduced system is capable of filling various gaps in the field of construction safety training, especially for working at heights activities and using PPE and safety harness. In addition, the workers participated in V-SAFE.vs2 training sessions stated that learning safety components via game-based safety training tools is more interactive and enjoyable compared to traditional training methods (e.g., classroom meetings, presentations, and guides). They also pointed out that such safety training tools do not require prior game or computer experience to receive training in the virtual environment since V-SAFE.vs2 has user-friendly functions such as click and point mechanism. According to the feedbacks from the workers, V-SAFE.vs2 provides invaluable opportunities to practice high-risk construction activities in a risk-free environment. As in previous studies (e.g. [18, 45, 50], V-SAFE.v2 also enables players to practice the construction tasks interactively in a risk-free environment. The serious games 
allow participants to make their own decision and virtually experience the consequences of their actions as provided in this tool.

Zhou et al. [39] highlighted that effective and reliable innovative training platforms should be available especially for high-risk activities that cause catastrophic accidents. V-SAFE.v2 meets this crucial requirement by integrating scaffolding and formwork activities. In the literature, only a few studies (e.g. [51-52]) focus on the development of a serious game for the specific construction tasks which require skillful activities of labors. Moreover, few studies [27, 42] have considered integrating potential accident scenarios in the game based safety training tools. In this regard, V-SAFE.v2 has this unique Testing Module feature where the real accident scenarios take place. The use of guardrails and PPEs [3] is crucial to prevent accidents on construction sites. An effective training tool should emphasize the use of all these accident prevention elements, which are provided by V-SAFE.v2. Li and colleagues [18] stated that safety training tools should simulate the real construction site dynamics, such as the collaborative working environment. In this sense, V-SAFE.v2 offers a suitable environment for construction tasks requiring collaboration.

The autonomous agents support V-SAFE.v2, which may lead to an accident in the Testing Module 2. These non-playable characters are used in the first Testing Module to provide a multi-user game environment when only a single participant receives the safety training. In this way, it is easy to evaluate the individual performance of trainees without any external influence during the testing stage. Although a single trainee performs all the tasks correctly, he or she might be exposed to accidents due to the unsafe behaviour of the autonomous agents in the Testing Module-2.

The construction workers have the responsibility to perform the construction tasks in compliance with safety rules, not only for their safety but also for their crew. Therefore, enabling collaboration in the virtual environment is crucial even though a single participant receives training. Accordingly, they can experience the consequences of their actions for their team members as well. To give an example, a real player who forgets locking the pins to connect the $\mathrm{H}$ bars could result in scaffold collapse in the Testing Module 1. In such a case, all workers on the scaffold fall from a height due to the wrong action of a team member and have an accident together (Figure 7).

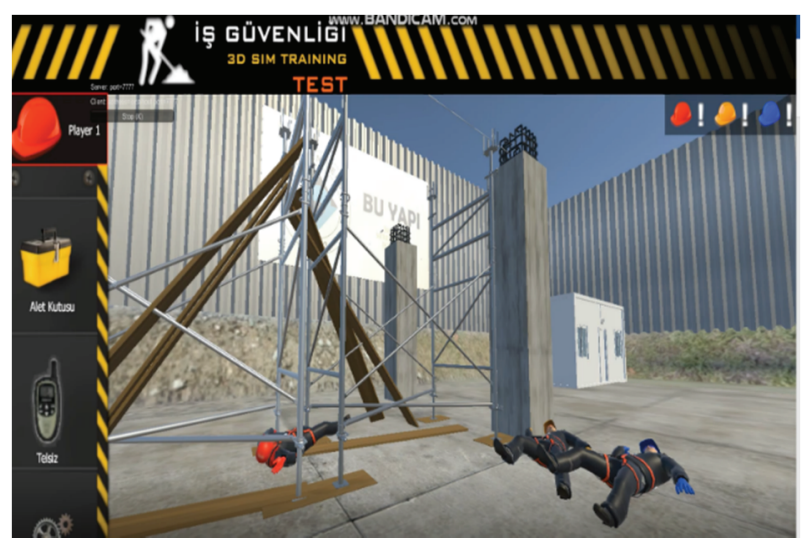

Figure 7 - Scaffold collapse 
When the scaffold collapses, the training simulation ends, and participants are not able to complete all construction tasks. Regardless of whether the team has completed the tasks, the performance of each user is reported individually on the screen via the LMS (Figure 8). Accordingly, the trainees can see their wrong actions and their consequences. Based on their performance, a quantitative score is also calculated. All of these features are essential for providing individual feedbacks and for the trainees to retain the acquired knowledge for a long time.

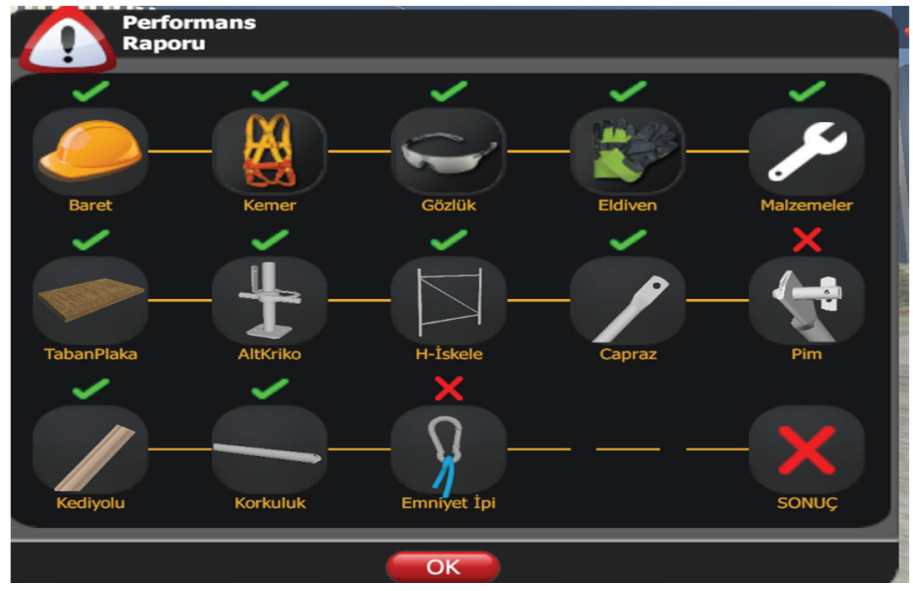

Figure 8 - Performance report of one player

In this way, trainees can develop an understanding of the occupational safety culture and consciousness about accidents through a different perspective. It is also important to highlight that the scoring system of V-SAFE.v2 is quite different from other safety training tools due to the consideration of the risk levels of activities. The LMS automatically calculates the performance scores of participants and provides detailed feedback at each step in Testing Modules 1 and 2.

Although experiments have been usually conducted with students in many of the existing studies [27, 30], we have utilized real construction workers and engineers to measure the applicability of V-SAFE.v2 in this study. The main motivation behind this study is to develop a user-friendly and game engine-based safety training for the construction industry. Thus, even the construction workers who do not have any computer or gaming experience easily adopted game-based training. An advanced serious game approach, consisting of high-risk accident scenarios, multi-user interactive training platform, user-friendly properties, and performance feedback reports, can have a significant impact on reducing human-induced construction safety issues.

\section{LIMITATION}

Occupational safety and health issues are highly complex due to the working conditions of the construction workplaces. Such complex, hazardous and dynamic conditions of the 
construction sites should be represented in the safety training tool. However, this study aims to create a road map to develop a safety training tool by using serious games, not to develop a commercial product. By using the knowledge gained through the development of $\mathrm{V}$ SAFE.v2, a need-specific and more comprehensive safety training tool can be developed. In this study, we used the latest simulation technologies to understand how to design a highly engaging and effective safety training tool for scaffolding and formwork construction. Therefore, we recognize that this study has limitations, which suggest directions for further research. First of all, V-SAFE.v2 could have a more realistic visual design to represent all the construction site components. Providing real site conditions and including dynamic factors of the construction workplaces are crucial to enable more reliable safety training to the trainees. Accordingly, a more realistic visual design can help workers better visualize the hazards before facing them on site. So, more emphasis can be given to the visual design of the tool. Moreover, although the accident rates of the scenario in V-SAFE.v2 were calculated based on a previous study [47], those rates can be easily revised concerning local conditions. Therefore, in the current version of V-SAFE.v2, the weight of the accident scenarios focusing on "improper behavior of the worker" and "PPE use" can be considered as another limitation of this study. The experiments can be also carried out with a higher number of participants to statistically evaluate the effectiveness of V-SAFE.v2, which is an important research question. As future research, the effectiveness of serious game-based safety training tool should be evaluated quantitatively. Moreover, the effectiveness of the developed game-based safety training tool can be compared to traditional training methods in future studies. In addition, since V-SAFE.vs2 has the opportunity of providing safety training for three different trainees together in the same virtual environment. The impact of such interaction between participants while performing construction activities on their safety performance could be assessed in future studies.

\section{CONCLUSION}

Even though occupational health and safety issues are of great concern in the construction industry, the training programs are not adequate to meet the actual demands of site safety conditions. On the other hand, serious games have various benefits that have been proven to provide a realistic and effective training environment for trainees. By using game technology, it is possible to simulate high-risk construction activities in a multi-user virtual training platform. In this study, we introduced a game-engine based safety training tool called V-SAFE.v2 for scaffolding and formwork construction. The main objective of this study is to develop a more effective and reliable training environment consistent with real construction site conditions. V-SAFE.v2 consists of Training Module and Testing Modules in which the safety performance of participants is evaluated. A case study was conducted with real construction workers and site engineers to assess the effectiveness of V-SAFE.v2. The findings of the case study show that V-SAFE.v2 is effective and reliable in providing highly engaging training for high-risk construction tasks. It is also highlighted by the participants that the V-SAFE.v2 has a great potential to raise worker's awareness and prevent fatal accidents. In summary, conveniently developing safety knowledge is possible through using serious games. 


\section{Acknowledgement}

We would like to acknowledge the support of the Scientific and Technological Research Council of Turkey (TUBITAK) within Grant No. 315M186.

\section{References}

[1] ILO, Cases of Fatal Occupational Injury by Economic Activity. $<$ https://www.ilo.org/ilostat/faces/ilostat-home/home?_adf.ctrlstate=ry1pcdok9_4\&_afrLoop=4059311599607201\#!> , 2019.

[2] BLS, National Census of Fatal Occupational Injuries in 2017. $<$ https://www.bls.gov/news.release/pdf/cfoi.pdf $>, 2018$.

[3] Haslam, R. A., Hide, S. A., Gibb, A. G. F., Gyi, D. E., Pavitt, T., Atkinson, S., and Duff, A. R., Contributing Factors in Construction Accidents. Applied Ergonomics, 36(4), 401-415, 2005.

[4] Guo, H., Yu, Y., and Skitmore, M., Visualization Technology-Based Construction Safety Management: A Review. Automation in Construction, 73, 135-144, 2017.

[5] Kale, Ö. A., and Baradan, S., Identifying Factors that Contribute to Severity of Construction Injuries using Logistic Regression Model. Teknik Dergi, 31(2), 99199940, 2020.

[6] Baradan, S., Akboğa, Ö., Çetinkaya, U., and Usmen, M. A., Ege Bölgesindeki İnşaat İş Kazalarının Sıklık ve Çapraz Tablolama Analizleri. İMO Teknik Dergi, 7345(7370), 448, 2016

[7] Tözer, K. D., Çelik, T., and Gürcanlı, E., Classification of Construction Accidents in Northern Part of Cyprus. Teknik Dergi, 29(2), 8295- 8316, 2018.

[8] Uzun, İ. M., Öztürk, D., \& Gürcanlı, G. E., Mimari Restorasyon ve Konservasyon Projelerinde İşçi Sağlığı ve İş Güvenliği Uygulamaları. Teknik Dergi, 31(5), 2020.

[9] Abdelhamid, T. S., and Everett, J. G., Identifying Root Causes of Construction Accidents. Journal of Construction Engineering and Management, 126(1), 52-60, 2017.

[10] Tam, V. W. Y., and Fung, I. W. H., Tower Crane Safety in the Construction Industry: A Hong Kong Study. Safety Science, 49(2), 208-215, 2011.

[11] Zhao, D., Thabet, W., McCoy, A., and Kleiner, B., Electrical Deaths in the US Construction: An Analysis of Fatality Investigations. International Journal of Injury Control and Safety Promotion, 21(3), 278-288, 2014.

[12] Winge, S., Albrechtsen, E., and Mostue, B. A., Causal Factors and Connections in Construction Accidents. Safety Science, 112, 130-141, 2019.

[13] Zhao, D., and Lucas, J., Virtual Reality Simulation for Construction Safety Promotion. International Journal of Injury Control and Safety Promotion, 22(1), 57-67, 2015.

[14] Jeschke, K. C., Kines, P., Rasmussen, L., Andersen, L. P. S., Dyreborg, J., Ajslev, J., 
Kabel, A., Jensen, E., and Andersen, L. L., Process Evaluation of A Toolbox-Training Program for Construction Foremen in Denmark. Safety Science, 94, 152-160, 2017.

[15] Hinze, J., Improving Safety Performance on Large Construction Sites. CIB Working Commission W, 99, 2003.

[16] Goldenhar, L. M., Moran, S. K., and Colligan, M., Health and Safety Training in A Sample of Open-Shop Construction Companies. Journal of Safety Research, 32(2), 237-252, 2001.

[17] Burke, M. J., Sarpy, S. A., Smith-Crowe, K., Chan-Serafin, S., Salvador, R. O., and Islam, G., Relative Effectiveness of Worker Safety and Health Training Methods. American Journal of Public Health, 96, 315-324, 2006.

[18] Li, X., Yi, W., Chi, H. L., Wang, X., and Chan, A. P. C., A Critical Review of Virtual and Augmented Reality (VR/AR) Applications in Construction Safety. Automation in Construction, 86, 150-162, 2018.

[19] Dawood, N., Miller, G., Patacas, J., and Kassem, M., Combining Serious Games and 4D Modelling for Construction Health and Safety Training. Computing in Civil and Building Engineering, 2087-2094, 2014.

[20] Martens, A., Diener, H., and Malo, S., Game-Based Learning with Computers Learning, Simulations, and Games. Transactions on Edutainment, 172-190, 2008.

[21] Gao, Y., González, V. A., and Yiu, T. W., Serious Games vs. Traditional Tools in Construction Safety Training: A Review. Proceedings of the Joint Conference on Computing in Construction (JC3), Heraklion, Greece, 655-662, 2017.

[22] Kuindersma, E., Field, J., and Pal, J., Game-Based Training for Airline Pilots. Conference: Simulation-Based Training For The Digital Generation, London, UK, 2015

[23] Kneebone, R. L., Practice, Rehearsal, and Performance: An Approach for SimulationBased Surgical And Procedure Training. JAMA, 302(12), 1336-1338, 2009.

[24] Mun, Y., Oprins, E., Van Den Bosch, K., Van Der Hulst, A., and Schraagen, J. M., Serious Gaming for Adaptive Decision Making of Military Personnel. Proceedings of the Human Factors and Ergonomics Society, Los Angeles, CA, 1168-1172, 2017.

[25] Sacks, R., Perlman, A., and Barak, R., Construction Safety Training Using Immersive Virtual Reality. Construction Management and Economics, 31(9), 1005-1017, 2013.

[26] Hasanzadeh, S., Esmaeili, B., and Dodd, M. D., Impact of Construction Workers' Hazard Identification Skills on Their Visual Attention. Journal of Construction Engineering and Management, 143(10): 04017070, 2017.

[27] Pedro, A., Le, Q. T., and Park, C. S., Framework for Integrating Safety into Construction Methods Education Through Interactive Virtual Reality. Journal of Professional Issues in Engineering Education and Practice, 142(2), 2015.

[28] Bosché, F., Abdel-Wahab, M., \& Carozza, L., Towards A Mixed Reality System for Construction Trade Training. Journal of Computing in Civil Engineering, 30(2): 
04015016, 2015

[29] Fang, Y., and Teizer, J., A Multi-User Virtual 3D Training Environment to Advance Collaboration Among Crane Operator and Ground Personnel in Blind Lifts. Computing in Civil and Building Engineering, 2014, 2071-2078, 2014.

[30] Dickinson, J. K., Woodard, P., Canas, R., Ahamed, S., and Lockston, D., Game-Based Trench Safety Education: Development and Lessons Learned. Electronic Journal of Information Technology in Construction, 16(8), 119-134, 2011.

[31] OSHA, Commonly Used Statistics: Construction's 'Fatal Four. $<$ https://www.osha.gov/oshstats/commonstats.html>, 2017

[32] Jeong, B. Y., Occupational Deaths and Injuries in the Construction Industry. Applied Ergonomics, 29(5), 355-360, 1998.

[33] Huang, X., and Hinze, J., Analysis of Construction Worker Fall Accidents. Journal of Construction Engineering and Management, 129(3): 262-271, 2003.

[34] OSHA, Safety and Health Topics: Scaffolding. <https://www.osha.gov/SLTC/scaffolding/construction.html>, 2017.

[35] Rubio-Romero, J. C., Carmen Rubio Gámez, M., and Carrillo-Castrillo, J. A., Analysis of the Safety Conditions of Scaffolding on Construction Sites. Safety Science, 55, 160 164,2013

[36] Gürcanli, G. E., and Müngen, U., Analysis of Construction Accidents in Turkey and Responsible Parties. Industrial Health, 51, 581-595, 2013.

[37] Hallowell, M. R., and Gambatese, J. A., Activity-Based Safety Risk Quantification for Concrete Formwork Construction. Journal of Construction Engineering and Management, 135(10): 990-998, 2013.

[38] López-Arquillos, A., Rubio-Romero, J. C., Gibb, A. G. F., and Gambatese, J. A., Safety Risk Assessment for Vertical Concrete Formwork Activities in Civil Engineering Construction. Work, 49(2), 183-192, 2014.

[39] Zhou, Z., Goh, Y. M., and Li, Q., Overview and Analysis of Safety Management Studies in the Construction Industry. Safety Science, 72, 337-350, 2015.

[40] Hsiao, H., Simeonov, P., Dotson, B., Ammons, D., Kau, T. Y., and Chiou, S., Human Responses to Augmented Virtual Scaffolding Models. Ergonomics, 48(10), 1223 $1242,2005$.

[41] Bilir, S., Gürcanli, G.E., A Method For Determination of Accident Probability in Construction Industry. Teknik Dergi, DOI: 10.18400/tekderg.363613, 29 (4), 85378561, 2018.

[42] Le, Q. T., Pedro, A., \& Park, C. S., A Social Virtual Reality Based Construction Safety Education System for Experiential Learning. Journal of Intelligent \& Robotic Systems, 79(3-4), 487-506, 2015.

[43] Baradan, S., and Usmen, M. A., Comparative injury and fatality risk analysis of 
building trades. J. Constr. Eng. Manage., 132(5), 533-539, 2006.

[44] Li, H., Lu, M., Hsu, S. C., Gray, M., and Huang, T., Proactive Behavior-Based Safety Management for Construction Safety Improvement. Safety Science, 75, 107-117, 2015.

[45] Guo, H., Li, H., Chan, G., and Skitmore, M., Using Game Technologies to Improve the Safety of Construction Plant Operations. Accident Analysis and Prevention, 48, 204$213,2012$.

[46] Kiral, I. A., Comu, S., and Kavaklioglu, C., Enhancing the Construction Safety Training by Using Virtual Environment: V-SAFE." 5th International/1 $1{ }^{\text {th }}$ Construction Specialty Conference, Vancouver, British Columbia, 161-169, 2015.

[47] Whitaker, S. M., Graves, R. J., James, M., and McCann, P., Safety with Access Scaffolds: Development of A Prototype Decision Aid Based on Accident Analysis. Journal of Safety Research, 34(3), 249-261, 2003.

[48] BLS, Fatal Occupational Injuries by Event or Exposure for All Fatalities and Major Private Industry Sector. <https://www.bls.gov/iif/oshwc/cfoi/cftb0249.pdf> (June. 7, 2019), 2011.

[49] Zhou, W., Whyte, J., \& Sacks, R., Construction Safety and Digital Design: A Review. Automation in Construction, 22, 102-111, 2012.

[50] Li, H., Chan, G., and Skitmore, M., Visualizing Safety Assessment by Integrating the Use of Game Technology. Automation in Construction, 22, 498-505, 2012.

[51] Li, H., Lu, M., Chan, G., and Skitmore, M., Proactive Training System for Safe and Efficient Precast Installation. Automation in Construction, 49, 163-174, 2015.

[52] Irizarry, J., \& Abraham, D. M., Application of Virtual Reality Technology for the Improvement of Safety in the Steel Erection Process. Computing in Civil Engineering. $1-11,2005$. 